\title{
CARDIOPULMONARY FITNESS AND MUSCLE STRENGTH IN PATIENTS WITH OSTEOGENESIS IMPERFECTA TYPE I
}

\author{
Tim Takken, MSc, PhD, Heike C. Terlingen, MSc, Paul J. M. Helders, PCS, MSc, PhD, Hans Pruis, MD, PhD, \\ Cornelis K. van Der Ent, MD, PhD, and Raoul H. H. Engelbert, PCS, PhD
}

\begin{abstract}
Objective To evaluate cardiopulmonary function, muscle strength, and cardiopulmonary fitness $\left(\mathrm{VO}_{2} \mathrm{peak}\right)$ in patients with osteogenesis imperfecta (OI).

Study design In 17 patients with OI type I (mean age $13.3 \pm 3.9$ years) cardiopulmonary function was assessed at rest using spirometry, plethysmography, electrocardiography, and echocardiography. Exercise capacity was measured using a maximal exercise test on a bicycle ergometer and an expired gas analysis system. Muscle strength in shoulder abductors, hip flexors, ankle dorsal flexor, and grip strength were measured. All results were compared with reference values.
\end{abstract}

Results Cardiopulmonary function at rest was within normal ranges, but when it was compared with normal height for age and sex, vital capacities were reduced. Mean absolute and relative $V_{2}$ peak were respectively $-1.17( \pm 0.67)$ and -1.41 $( \pm 1.52)$ standard deviations lower compared with reference values $(P<.01)$. Muscle strength also was significantly reduced in patients with $O I$, ranging from $-1.24 \pm 1.40$ to $-2.88 \pm 2.67$ standard deviations lower compared with reference values.

Conclusions In patients with OI type I, no pulmonary or cardiac abnormalities at rest were found. The exercise tolerance and muscle strength were significantly reduced in patients with OI, which might account for their increased levels of fatigue during activities of daily living. (J Pediatr 2004;145:813-8)

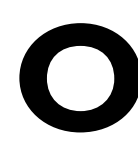
steogenesis imperfecta (OI) is a congenital connective tissue disorder. The biochemical basis in most cases involves a quantitative or qualitative abnormality in the biosynthesis of type I collagen, the principle organic component of the skeleton. ${ }^{1}$ The most common mode of transmission is autosomal dominant; in rare instances it is autosomal recessive. OI is a disorder of remarkable clinical variability, and it consists of several subtypes of which type I is the least severe, with a normal life expectancy. Major clinical characteristics of OI type I include recurrent fractures from osteopenia that often result in short stature and skeletal deformity. Additional clinical manifestations of this disease type are blue sclera, dentinogenesis imperfecta, joint laxity, and maturity-onset deafness in $50 \%$ of patients. ${ }^{2}$ OI has, depending on the severity of the disease, a large impact on functional ability. In OI type I, all patients are at least neighborhood walkers.

Intolerance for exercise is an often-heard complaint from patients with $\mathrm{OI}$ and their parents. Fatigue limits patients with $\mathrm{OI}$ in their activities of daily living. These complaints are usually interpreted as a combination of proximal muscle weakness and generalized hypermobility of the joints. However, heart, lungs, and other organ systems could be involved as well, as collagen I is an important component of these organ systems.

However, chronically ill patients often display a subnormal exercise capacity. This is usually a result of two main causes: hypoactivity that leads to detraining and specific pathophysiological factors that limit one or more exercise-related functions. ${ }^{3}$

The objective of this present study was to evaluate the pulmonary function, cardiac function, muscle strength, and $\mathrm{VO}_{2}$ peak in patients with OI type I.

\begin{tabular}{llll}
\hline BUA & Broadband ultrasonography attenuation & RER & Respiratory exchange ratio \\
FEV & Forced expiratory volume in I second & SOS & Speed of sound \\
FVC & Forced vital capacity & TLC & Total lung capacity \\
HR & Heart rate & $\mathrm{VO}_{2}$ peak & Cardiopulmonary fitness \\
OI & Osteogenesis imperfecta & & \\
\hline
\end{tabular}

\footnotetext{
From the Departments of Pediatric Physical Therapy \& Exercise Physiology, Orthopedics, and Pediatric Pulmonology, Wilhelmina Children's Hospital, University Medical Center Utrecht, The Netherlands.

Submitted for publication Mar I, 2004; last revision received Jul 8, 2004; accepted Aug 3, 2004

Reprint requests: Tim Takken, MSc, PhD, Department of Pediatric Physical Therapy \& Exercise Physiology, Wilhelmina Childrens's Hospital, University Medical Center Utrecht, Room KB2.056.0, PO Box 85090, NL 3508 AB Utrecht, The Netherlands. E-mail: t.takken@wkz.azu.nl. 0022-3476/\$ - see front matter Copyright (C) 2004 Elsevier Inc. All rights reserved.

10. 10 | 6/j.jpeds.2004.08.003
} 


\section{METHODS}

We examined 17 consecutive patients $(15$ girls and 2 boys, mean age $13.3 \pm 3.9$ years, range $8-21$ years) with OI type I out of the pediatric orthopedic outpatient clinic from the Wilhelmina Children's Hospital Utrecht, a national referral center for OI. All were at least household walkers as classified according to the modified Bleck score. ${ }^{4}$ We included only patients with OI type I because they have the least fracture-risk during maximal exercise. All patients and parents gave informed consent before participation. This study was approved by the Medical Ethics Committee of the University Medical Center Utrecht.

Oral bisphosphonates were administered in 1 girl; whereas others did not use medication. No children had fractures in the 6 months before the start of the study. Before the maximal exercise test, an extensive cardiac and pulmonary examination was performed to exclude possible contraindications for exercise testing.

\section{Anthropometry}

Standing height, sitting height, arm span, and weight were measured in a standardized manner without wearing shoes and heavy clothing to the nearest centimeter and $100 \mathrm{~g}$, respectively. ${ }^{5}$ The values of height, sitting height, and weight were compared with reference values for healthy subjects matched for age and sex, and the $Z$ scores were calculated. ${ }^{5}$

\section{Joint Hypermobility}

The extent of generalized hypermobility of the joints was quantified using the hypermobility score of Bulbena et al. ${ }^{6}$ The presence of hypermobility was scored in nine joints (thumb, metacarpophalangeal V, elbow-, shoulder-, hip-, knee-, patella-, ankle- and metatarsophalangeal I joint), and the presence of ecchymoses was recorded (maximum score: 10 points). Generalized hypermobility of the joints was considered present when the score was at least 5 in females and at least 4 in males. ${ }^{6}$

\section{Muscle Strength}

The Hand Held Dynamometer (Citec dynamometer type CT 3001, CIT Technics, Groningen, the Netherlands) was used to measure the isometric muscle strength (in Newton) in the shoulder abductors, hip flexors, ankle dorsal flexor, and grip strength bilaterally. Muscle strength of the nondominant side was compared with reference values for healthy subjects matched for age and sex. Reference values for muscle force of healthy subjects 8 to 18 years of age were obtained from studies on healthy Dutch children (see section, Reference Values).

\section{Bone Mineral Density}

Quantitative ultrasonography measurement was performed as a non-invasive method of bone quantity assessment and provides information of bone structure..$^{7-9}$ Broadband ultrasonography attenuation (BUA) and speed of sound (SOS) on the right os calcis were measured using the Sahara ultrasonography device clinical bone sonometer (Hologic QDR 4500, Hologic Inc, Waltham, Mass). Both measures were compared with reference values matched for age and sex from healthy Dutch adolescents ranging from 8 to 18 years of age. An acoustic phantom provided by the manufacturer was scanned daily before the measurements and showed no drift over the time period of the study.

\section{Pulmonary Function}

Spirometry and body plethysmography were performed using a pneumotach system and a volume-constant plethysmograph (Master Lab system, E. Jaeger, Würzburg, Germany). Lung function measurements included peak expiratory flow, forced expiratory volume in 1 second $\left(\mathrm{FEV}_{1}\right)$, maximal expiratory flow at $50 \%$ and at $75 \%$ expired volume, forced vital capacity (FVC), and total lung capacity (TLC). The results were compared with predicted values for healthy subjects matched for age, body height, and sex..$^{10,11}$ Because growth can be disproportionately disturbed in children with OI, actual pulmonary function parameters also were compared with predicted values of children with a mean height for sex and age (predicted values for normalize height).

\section{Cardiac Function}

In each patient a 12-lead electrocardiogram was recorded. Also, a complete echocardiogram was performed by a pediatric cardiologist, including two-dimensional imaging, color flow mapping, spectral Doppler, and M-mode assessment of left ventricular function using a Vivid 7, GE Medical Ultrasound system (Milwaukee, Wis). This procedure makes it possible to assess and quantitate non-invasively certain aspects of cardiac anatomy and function. M-mode measurements were compared with predicted values for healthy subjects matched for age and sex. ${ }^{12}$ Resting blood pressure was measured using the non-invasive automated Omron R3 (CEMEX Medical Technics, Nieuwegein, the Netherlands). ${ }^{13}$

\section{Maximal Exercise Test}

Subjects performed a maximal exercise test using an electronically braked cycle ergometer (Lode Examiner, Lode BV, Groningen, the Netherlands). The work rate was increased 10,15 , or $20 \mathrm{~W} /$ minute depending on estimated fitness level to bring the patient to his or her limit between 8 and 12 minutes of exercise. ${ }^{14}$ This protocol continued until the patient stopped because of volitional exhaustion, despite strong verbal encouragement of the investigators. During the maximal exercise test, subjects breathed through a face mask (Hans Rudolph Inc, Kansas City, MO) connected to a calibrated expired gas analysis system (Oxycon Champion, Viasys, Bilthoven, the Netherlands). Expired gas was passed through a flowmeter, an oxygen analyzer, and a carbon dioxide analyzer. The flow meter and gas analyzers were connected to a computer, which calculated breath-by-breath minute ventilation, oxygen uptake, carbon dioxide production, and respiratory exchange ratio (RER) from conventional equations. Heart rate (HR) was measured continuously during 


\begin{tabular}{|c|c|c|c|c|}
\hline & $\begin{array}{l}\text { Ol type I }(N=17) \\
\text { mean } \pm S D(\text { range })\end{array}$ & $\begin{array}{c}Z \text { score } \\
\text { mean } \pm \text { SD }\end{array}$ & $\begin{array}{l}\text { Ref values } \\
\text { mean } \pm \text { SD }\end{array}$ & $P$ value \\
\hline Height (m) & $1.47 \pm 0.16(1.22-1.71)$ & $-1.41 \pm .911$ & $1.57 \pm 0.13$ & $.05^{*}$ \\
\hline Sitting height $(\mathrm{cm})$ & $75.3 \pm 8.0(64.0-89.0)$ & $-2.17 \pm 1.29$ & $82.6 \pm 6.7$ & $<.01^{\dagger}$ \\
\hline Arm span $(\mathrm{cm})$ & $147.5 \pm 15.4(125-175)$ & $-1.28 \pm 0.70$ & $159.35 \pm 15.8$ & $<.01^{\dagger}$ \\
\hline Weight $(\mathrm{kg})$ & $44.2 \pm 12.3(27.2-68.5)$ & $-0.15 \pm 0.99$ & $45.3 \pm 11.4$ & $.8 \mathrm{NS}$ \\
\hline $\mathrm{BUA}\left(\text { in } \mathrm{dB} \cdot \mathrm{MHz}^{-1}\right)^{\ddagger}$ & $43.37 \pm 13.07(21-65)$ & $-1.76 \pm 1.05$ & $64.0 \pm 15.7$ & $.01^{\dagger}$ \\
\hline $\operatorname{SOS}\left(\text { in } m \cdot s^{-1}\right)^{\ddagger}$ & $|506.6| \pm 23.58(\mid 466-1547)$ & $-2.22 \pm 1.2$ & $1564 \pm 28$ & $.01^{\dagger}$ \\
\hline
\end{tabular}

Ref values, reference values from healthy Dutch subjects.

${ }^{*} P$ value $<.05$.

$\dagger P$ value $<.01$.

$\ddagger \mathrm{N}=16$.

the maximal exercise test by a bipolar electrocardiogram. Absolute peak oxygen uptake $\left(\mathrm{VO}_{2}\right.$ peak $)$ was taken as the average value over the last 30 seconds during the maximal exercise test. Relative $\mathrm{VO}_{2}$ peak $\left(\mathrm{VO}_{2}\right.$ peak $\left./ \mathrm{kg}\right)$ was calculated as absolute $\mathrm{VO}_{2}$ peak divided by body mass. Predicted $\mathrm{VO}_{2}$ peak values were obtained from established values from age- and sex- matched historical Dutch controls. ${ }^{15}$

\section{Reference Values}

The reference values for bone mineral density and muscle strength were obtained from a study of healthy school children, which comprises subjects ranging from 8 to 19 years of age who were followed at two schools in the city of Zeist, the Netherlands. Two hundred and eighty-four subjects agreed to participate, and parents or subjects gave written informed consent. The subjects were examined during special sessions at school over a period of 3 weeks in the spring of 2002. Data on children ranging from 8 to 10 years of age have been published ${ }^{16}$; whereas the data on adolescents are submitted for publication (Engelbert et al, submitted).

\section{Statistics}

Statistical analyses were performed using the Statistical Package for the Social Sciences for Windows (version 10.0, SPSS Inc, Chicago, Ill). Normally distribution of the data was confirmed using the one-sample Kolmogorov-Smirnov test. Variables with normal distribution were expressed as means, standard deviations, and range; statistical comparisons between measurements were made by using the Student's $t$ test. The data also were expressed as the percent of predicted values or as $Z$ scores. Associations between measurements and $\mathrm{VO}_{2}$ peak were calculated using Pearson's correlations. Alpha level was set at $P<.05$ for all analyses.

\section{RESULTS}

There were 2 patients with two intramedullary rods each in the lower extremities, and there were 2 patients with three rods each in the lower extremities. On clinical examination, no scoliosis or kyphotis were detected in our patients. In patients with OI type I, weight was almost comparable to the healthy population. The sitting height, body height, and arm span
Table II. Actual values (mean \pm SD) of pulmonary function tests and values expressed as percentage predicted, based on both actual and normalized height in patients with OI type I

\begin{tabular}{lccc}
\hline & $\begin{array}{c}\text { Actual } \\
\text { values }\end{array}$ & $\begin{array}{c}\text { Percentage } \\
\text { of predicted } \\
\text { actual height }\end{array}$ & $\begin{array}{c}\text { Percentage } \\
\text { of predicted } \\
\text { normalized } \\
\text { height }\end{array}$ \\
\hline $\mathrm{PEF}\left(\mathrm{L} \cdot \mathrm{s}^{-1}\right)$ & $5.7 \mathrm{I} \pm 1.50$ & $116.7 \pm 17.1$ & $97.4 \pm 15.3$ \\
$\mathrm{FEV}(\mathrm{L})$ & $2.41 \pm 0.66$ & $106.7 \pm 10.9$ & $88.0 \pm 8.1^{*}$ \\
$\mathrm{MEF} \mathrm{50}\left(\mathrm{L} \cdot \mathrm{s}^{-1}\right)$ & $3.60 \pm 0.71$ & $126.0 \pm 22.8$ & $112.8 \pm 19.0$ \\
$\mathrm{MEF} \mathrm{25}\left(\mathrm{L} \cdot \mathrm{s}^{-1}\right)$ & $1.64 \pm 0.43$ & $105.7 \pm 22.8$ & $86.8 \pm 18.9^{\dagger}$ \\
$\mathrm{FVC}(\mathrm{L})$ & $2.60 \pm 0.76$ & $99.5 \pm 9.6$ & $81.8 \pm 7.8^{*}$ \\
TLC (L) & $3.29 \pm 0.93$ & $133.1 \pm 32.9$ & $106.3 \pm 29.2$ \\
\hline
\end{tabular}

$P E F$, Peak expiratory flow; $M E F 50$, maximal expiratory flow rate at $50 \%$ expired volume; $M E F 25$, maximal expiratory flow at $75 \%$ expired volume; $R V$, residual volume.

${ }^{*} P$ value $<.001$

$\dagger P$ value $<.01$

were significantly reduced $(P<.05$; Table I). Generalized hypermobility was present in 1 boy (Bulbena score: 4 ) and in 3 girls (Bulbena score: 5, 7, and 8, respectively). The median Bulbena score was 2 (SD: 2.4, IR: 1-4). The median Bleck score was 8 (SD: 2, IR: 4-9), indicating that most of the patients were community walkers. In all muscle groups, a significant reduction in strength was found compared with reference values $(P<.05$; Table III).

One patient was excluded from the bone mineral density analyzes because she used oral biphosphonates. Her BUA and SOS were obviously different from the rest of the subjects $(Z$ score BUA: +3.88, $Z$ score SOS: +0.60$)$. Her other measurements did not differ from the other patients in this group. A large significant decrease in bone mineral density (bone quantity as well as bone stiffness) was found as compared with age-matched controls $(P<.01$; Table I).

All patients were successful in generating technically acceptable flow-volume curves. Almost all measures of pulmonary function were normal or better compared with the reference values for actual height of the subjects. No 


\begin{tabular}{lcccc}
\hline & $\begin{array}{c}\text { OI type I }(\mathbf{n}=\mathbf{~ I 7}) \\
\text { mean } \pm \text { SD }(\text { range) }\end{array}$ & $\begin{array}{c}\text { Z score mean } \pm \text { SD } \\
\text { (range) }\end{array}$ & $\begin{array}{c}\text { Ref values } \\
\text { mean } \pm \\
\text { SD }\end{array}$ & $\begin{array}{c}\boldsymbol{P} \\
\text { value }\end{array}$ \\
\hline Absolute $\mathrm{VO}_{2}$ peak $\left(\mathrm{L} \cdot \mathrm{min}^{-1}\right)$ & $1.48 \pm 0.36(0.96-2.13)$ & $-1.17 \pm 0.67(-2.50-0.12)$ & $1.82 \pm 0.33$ & $<.01^{*}$ \\
Relative $\mathrm{VO}_{2}$ Peak $\left(\mathrm{mL} \cdot \mathrm{kg}^{-1} \cdot \mathrm{min}^{-1}\right)$ & $34.57 \pm 7.82(22.34-52.82)$ & $-1.41 \pm 1.52(-3.35-1.60)$ & $41.8 \pm 3.8$ & $<.01^{*}$ \\
Shoulder abductor strength $(\mathrm{N})$ & $94.94 \pm 29.46(40-135)$ & $-1.24 \pm 1.40(-3.99-0.98)$ & $128 \pm 40$ & $.01^{*}$ \\
Grip strength $(\mathrm{N})$ & $65.75 \pm 31.89(22-116)$ & $-2.88 \pm 2.67(-9.30-0.43)$ & $102 \pm 41$ & $<.01^{*}$ \\
Hip flexor strength $(\mathrm{N})$ & $126.53 \pm 39.69(55-209)$ & $-1.78 \pm 0.88(-3.34-0.54)$ & $186 \pm 45$ & $<.01^{*}$ \\
Ankle dorsal flexor strength $(\mathrm{N})$ & $115.69 \pm 34.75(52-175)$ & $-1.84 \pm 1.33(-4.00-0.21)$ & $166 \pm 32$ & $<.01^{*}$ \\
\hline
\end{tabular}

Muscle strength was measured at the left side of the body; $N$, Newton; Ref values, reference values from healthy Dutch subjects.

${ }^{*} P$ value $<.05$.

significant differences with healthy subjects were found (Table II), and no obstructive or restrictive lung disease was present in these patients. The $\mathrm{FEV}_{1} / \mathrm{FVC}$ ratio was $93.4 \%+3.7 \%$. If actual lung function values were compared with reference values of children with a mean height for age and sex, a significant decrease of $\mathrm{FEV}_{1}$, maximal expiratory flow at $75 \%$, and FVC was observed; whereas TLC values were not different from controls (Table II).

Fifteen patients had a normal cardiac anatomy. One child had an ectopic atrial rhythm, and 1 child had mitral valve regurgitation, which was not clinically significant. Exercise capacity was not related to these findings. The first patient had a $\mathrm{VO}_{2}$ peak $Z$ score of $-0.87 \mathrm{SD}$; the latter patient had a $\mathrm{VO}_{2}$ peak $Z$ score of -0.7 , indicating low-normal exercise capacities. The mean systolic blood pressure was $111 \pm 14.5 \mathrm{~mm}$ $\mathrm{Hg}$; the mean diastolic blood pressure was $76.4 \pm 9.4 \mathrm{~mm} \mathrm{Hg}$.

The HRpeak and the RERpeak indicated that none of the patients terminated the maximal exercise test prematurely at a submaximal level (HRpeak $194 \pm 11$ beats $/ \mathrm{min}^{-1}$; RERpeak $1.1 \pm 0.1$ ), so the exercise effort could be classified as maximal for all the patients. The maximal ventilation during the exercise test was $53.6 \pm 10.4 \mathrm{~L} \cdot \mathrm{min}^{-1}$. Maximal voluntary ventilation (calculated as $\mathrm{FEV}_{1} \cdot 40^{17}$ ) was $96.3 \pm$ $26.3 \mathrm{~L} \cdot \mathrm{min}^{-1}$, which results in a breathing reserve of $42.5 \mathrm{~L}$. $\min ^{-1}$ (range $18-87 \mathrm{~L} \cdot \min ^{-1}$ ). The mean oxygen pulse $\left(\mathrm{VO}_{2}\right.$ peak/HRpeak) was $8.0 \pm 1.9 \mathrm{~mL} \cdot$ beat $^{-1}$. None of the oxygen pulse curves leveled off during the exercise test. Ten of 17 (59\%) patients had a large decrease of their absolute $\mathrm{VO}_{2}$ peak; whereas 5 of 17 (29\%) patients had a small or moderate decrease, and 2 of 17 (12\%) patients had almost normal values in comparison with their contemporaries. Twelve of 17 (71\%) patients had a large decrease of their $\mathrm{VO}_{2}$ peak/kg; 2 patients had a small decrease, 2 patients had a moderate increase, and 1 child had a large increase in his $\mathrm{VO}_{2}$ peak $/ \mathrm{kg}$ (whereas he had a moderate reduced $\mathrm{VO}_{2}$ peak) in comparison with their peers.

The correlation between $Z$ scores for $\mathrm{VO}_{2}$ peak and Bulbena score were $-0.302(P=.240)$ and $-.407(P=.1)$ for $\mathrm{VO}_{2}$ peak/kg and $\mathrm{VO}_{2}$ peak, respectively. There was a significant association between SOS and $\mathrm{VO}_{2}$ peak $(r=0.553$, $P=.026)$, and between SOS and $\mathrm{VO}_{2}$ peak $/ \mathrm{kg}(r=0.660$,
$P=.005)$. However, there were no significant associations between BUA and $\mathrm{VO}_{2}$ peak $/ \mathrm{kg}$ or $\mathrm{VO}_{2}$ peak $(r=0.3, P=.2$ for both correlations). A highly significant correlation between the mean $Z$ score of muscle strength and $\mathrm{VO}_{2}$ peak was found $(r=0.5, P=.05)$.

\section{DISCUSSION}

Cardiopulmonary fitness (expressed in $\mathrm{VO}_{2}$ peak and $\mathrm{VO}_{2}$ peak $/ \mathrm{kg}$ ) of the patients was significantly lower compared with healthy subjects. We found no evidence for circulatory abnormalities as a cause of the reduced fitness. Symptomatic mitral and aortic insufficiency in OI has been reported incidentally; whereas incidence and prevalence of heart diseases in OI type I are not published. ${ }^{18}$

When compared with reference values from heightmatched children, we found no abnormalities in lung function in children with OI. This is in line with findings of Falvo et al. ${ }^{19}$ However, in children with OI growth can be disturbed, affecting legs and arms more than the trunk and the lungs. Height was significantly reduced in our patient group (mean $Z$ score -1.41). Comparison with reference values from healthy children with normal growth can therefore overestimate the lung function values of children with OI. For this reason we also compared actual lung function values with reference values of children with a mean height for age and sex. This comparison showed normal TLC values in children with OI but significantly reduced values of $\mathrm{FVC}$ and $\mathrm{FEV}_{1}$. Although children with OI have normal total lung volumes, the emptying of the lung might be reduced because of thoracic stiffness. Sitting height is decreased because of collapsing of thoracic vertebrae, resulting in a more horizontal position of the ribs and pectus carinatum. We found no arguments for involvement of the lungs itself because the $\mathrm{FEV}_{1} / \mathrm{FVC}$ ratios were completely normal. The breathing reserve of the patients indicated that ventilatory limitations were not present during the exercise test. Moreover, the oxygen pulse curves of the patients did not level off during the exercise test, indicating that major cardiac disease or pulmonary vascular disease was not present. Thus, the fatigue complaints of patients with OI might only be related to proximal muscle weakness and a reduced $\mathrm{VO}_{2}$ peak. 
Although in OI type I generalized joint hypermobility is frequently present, ${ }^{4,20}$ no significant correlation between the degree of joint hypermobility and the exercise tolerance was found. Because generalized joint hypermobility is frequently observed in ankle, knee, and hip joint in young children with OI type I, the association between joint mobility and exercise tolerance might be present when using treadmill analysis instead of cycle ergometry for the assessment of exercise tolerance.

The bone mineral density of our patients was significantly lower compared with healthy subjects. Only SOS was significantly associated with exercise tolerance. A recent study found that SOS was a more sensitive indicator of the deterioration of the quality and quantity of bone as a result of insufficient weight-bearing exercise than BUA. ${ }^{21}$

The relationship between bone mineral density and exercise tolerance might be biased by the physical activity level of a subject. It is known from the literature that physical activity results in a increase in both exercise tolerance and bone mineral density. ${ }^{22,23}$

We found a high correlation between the mean $Z$ score of muscle strength and $\mathrm{VO}_{2}$ peak. Lower muscle strength may be caused by a decrease in muscle mass or by a reduced neuromuscular coordination. The patients in this study were untrained and did not participate in sport activities. There are several additional explanations for the diminished exercise tolerance of the patients with OI. Sedentary subjects have fewer capillaries in their muscles per cross-sectional area compared with subjects with an active lifestyle. ${ }^{24,25}$ Also, the activity of the oxidative enzymes is reduced and will result in a reduced capacity of the skeletal muscle to extract oxygen from the blood. ${ }^{26}$ Moreover, disease- or inactivity-induced skeletal muscle atrophy reduces the total amount of oxygen that can be consumed by the muscles. ${ }^{3}$ These factors will lead to an impaired oxygen extraction in the exercising muscle, higher mixed-venous oxygen content, and, finally, a reduced $\mathrm{VO}_{2}$ peak. Moreover, the shallow oxygen pulse increase during exercise does suggest a reduced maximal cardiac stroke volume in patients with OI. Because sedentary patients with OI with reduced $\mathrm{VO}_{2}$ peak are able to reach normal values of maximal heart rate during exercise (mean HRpeak 194), reduced maximal stroke volume is largely responsible for their reduced peak cardiac output and thus decreased $\mathrm{VO}_{2}$ peak (as cardiac output is the product of $\mathrm{HR}$ by stroke volume according to the Fick equation ${ }^{4}$ ).

Additionally, we found a low resting blood pressure in our patients. This might be because of the lower levels of collagen I in the blood vessels, which result in a higher laxity of blood vessels and a lower blood pressure and could result in a sub-optimal transport of oxygen, metabolites, and nutrients to and from muscles, and this may account for the reduced exercise capacity. We did not measure blood pressure, cardiac output, or blood gasses during exercise.

One of the shortcomings of this study is the comparison of patients with historical reference values. Another approach would be the use of control subjects. However, a selection bias in control subjects could lead to results that might not be representative for the normal population. In a recent position statement, the American Thoracic Society/American College of Chest Physicians recommends the use of reference values that best reflects the characteristics of the population peak exercise as tested and the equipment and methodology utilized. ${ }^{27}$ The reference values in this current study are the best available reference values for healthy Dutch children and adolescents and were established using the same instrumentation as the current research project. Moreover, because our sample included only 2 boys, in a future study more boys with OI type should be included.

Additional cardiovascular studies should be conducted to more specifically define the metabolic and cardiovascular bases of exercise intolerance in patients with OI type I. However, it is unclear as to whether the reduced $\mathrm{VO}_{2}$ peak and muscle strength are a consequence of a sedentary lifestyle or are a specific consequence of the impaired type I collagen synthesis. A weight-bearing exercise training intervention in patients with OI that aims to improve exercise tolerance and perhaps bone mineral density would be of interest.

We thank Dr Nigel A. S. Taylor and Dr Helge Hebestreit for their thorough review of the manuscript and their helpful comment.

\section{REFERENCES}

1. Sillence DO. Craniocervical abnormalities in osteogenesis imperfecta: genetic and molecular correlation. Pediatr Radiol 1994;24:427-30.

2. Vetter U, Pontz B, Zauner E, Brenner RE, Spranger J. Osteogenesis imperfecta: a clinical study of the first ten years of life. Calcif Tissue Int 1992; 50:36-41.

3. Bar-Or O. Pathophysiological factors which limit the exercise capacity of the sick child. Med Sci Sports Exerc 1986;18:276-82.

4. Engelbert RH, Uiterwaal CS, Gulmans VA, Pruijs H, Helders PJ. Osteogenesis imperfecta in childhood: prognosis for walking. J Pediatr 2000; 137:397-402.

5. Gerver W, De Bruin R. Peadiatric Morphometrics, A Reference Manual. Utrecht, the Netherlands: Bunge; 1996.

6. Bulbena A, Duro JC, Porta M, Faus S, Vallescar R, Martin-Santos R. Clinical assessment of hypermobility of joints: assembling criteria. J Rheumatol 1992;19:115-22.

7. Gluer CC, Wu CY, Jergas M, Goldstein SA, Genant HK. Three quantitative ultrasound parameters reflect bone structure. Calcif Tissue Int 1994;55:46-52.

8. Njeh CF, Boivin CM, Langton CM. The role of ultrasound in the assessment of osteoporosis: a review. Osteoporos Int 1997;7:7-22.

9. van Daele PL, Burger H, De Laet CE, Pols HA. Ultrasound measurement of bone. Clin Endocrinol (Oxf) 1996;44:363-9.

10. Rosenthal M, Bain SH, Cramer D, Helms P, Denison D, Bush A, et al. Lung function in white children aged 4 to 19 years, I: spirometry. Thorax 1993;48:794-802.

11. Rosenthal M, Cramer D, Bain SH, Denison D, Bush A, Warner JO. Lung function in white children aged 4 to 19 years, II: single breath analysis and plethysmography. Thorax 1993;48:803-8.

12. Kampmann C, Wiethoff CM, Wenzel A, Stolz G, Betancor M, Wippermann CF, et al. Normal values of $M$ mode echocardiographic measurements of more than 2000 healthy infants and children in central Europe. Heart 2000;83:667-72.

13. Eckert S, Gleichmann U, Zagorski O, Klapp A. Validation of the OMRON R3 blood pressure self-measuring device through simultaneous comparative invasive measurements according to protocol 58130 of the German Institute for Validation. Blood Press Monit 1997;2: 189-92. 
14. Buchfuhrer MJ, Hansen JE, Robinson TE, Sue DY, Wasserman K, Whipp BJ. Optimizing the exercise protocol for cardiopulmonary assessment. J Appl Physiol 1983;55:1558-64.

15. Binkhorst RA, van 't Hof MA, Saris WHM. Maximale inspanning door kinderen; referentiewaarden voor 6-18 jarige meisjes en jongens [Maximal exercise in children; reference values girls and boys, 6-18 year of age]. Den-Haag: Nederlandse Hartstichting; 1992.

16. Uiterwaal CS, Grobbee DE, Sakkers RJ, Helders PJ, Bank RA, Engelbert RH. A relation between blood pressure and stiffness of joints and skin. Epidemiology 2003;14:223-7.

17. Wasserman K, Hansen JE, Sue DY, Casaburi R, Whipp BJ. Principles of Exercise Testing and Interpretation. 3rd ed. Baltimore: Lippincott, Williams \& Wilkins; 1999

18. Wong RS, Follis FM, Shively BK, Wernly JA. Osteogenesis imperfecta and cardiovascular diseases. Ann Thorac Surg 1995;60:1439-43.

19. Falvo KA, Klain DB, Krauss AN, Root L, Auld PA. Pulmonary function studies in osteogenesis imperfecta. Am Rev Respir Dis 1973;108:1258-60.

20. Engelbert RH, Beemer FA, van der Graaf Y, Helders PJ. Osteogenesis imperfecta in childhood: impairment and disability—a follow-up study. Arch Phys Med Rehabil 1999;80:896-903.
21. Lehtonen-Veromaa M, Mottonen $T$, Kautiainen H, Heinonen OJ, Viikari J. Influence of physical activity and cessation of training on calcaneal quantitative ultrasound measurements in peripubertal girls: a 1 -year prospective study. Calcif Tissue Int 2001;68:146-50.

22. Kemper HCG, Niemeyer C. The importance of a physically active lifestyle during youth for peak bone mass. In: Blimkie CJR, Bar-Or O, ed. Nerw Horizons in Pediatric Exercise Science. Champaign, Ill: Human Kinetics Publishers; 1995:77-95.

23. Janz KF, Burns TL, Torner JC, Levy SM, Paulos R, Willing MC, et al. Physical activity and bone measures in young children: the Iowa Bone Development Study. Pediatrics 2001;107:1387-93.

24. Wagner PD. An integrated view of the determinants of maximum oxygen uptake. Advan Exper Med Biol 1988;227:245-56.

25. Saltin B, Blomqvist G, Mitchell JH, Johnson RL Jr, Wildenthal K, Chapman $\mathrm{CB}$. Response to exercise after bed rest and after training. Circulation 1968;38(suppl 5):VII1-VII78.

26. Holloszy JO, Coyle EF. Adaptations of skeletal muscle to endurance exercise and their metabolic consequences. J Appl Physiol 1984;56:831-8.

27. ATS/ACCP. ATS/ACCP Statement on cardiopulmonary exercise testing. Am J Respir Crit Care Med 2003;167:211-77.

Access to The Journal of Pediatrics Online is now reserved for print subscribers!

Full-text access to The Journal of Pediatrics Online is available for all print subscribers. To activate your individual online subscription, please visit The Journal of Pediatrics Online, point your browser to http://www.us.elsevierhealth.com/jpeds, follow the prompts to activate online access here, and follow the instructions. To activate your account, you will need your subscriber account number, which you can find on your mailing label (note: the number of digits in your subscriber account number varies from 6 to 10). See the example below in which the subscriber account number has been circled:

\section{Sample mailing label}

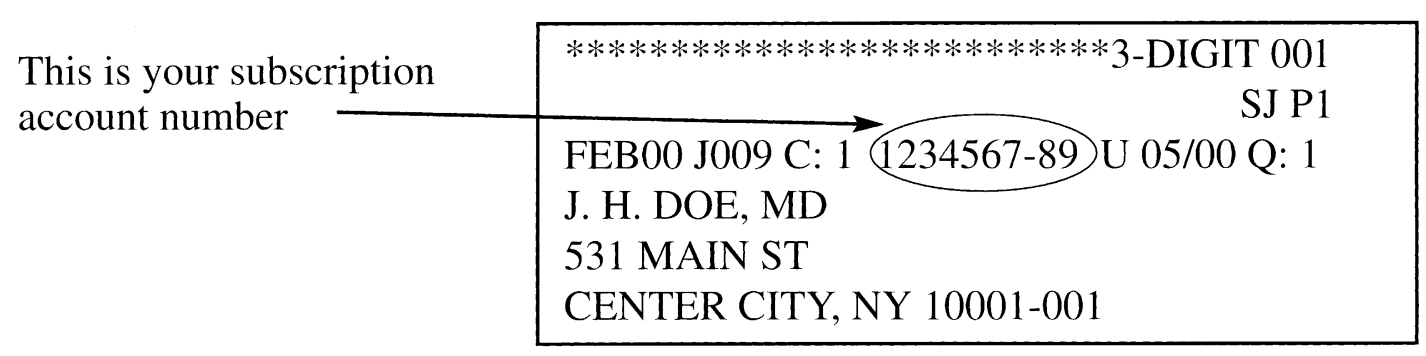

Personal subscriptions to The Journal of Pediatrics Online are for individual use only and may not be transferred. Use of The Journal of Pediatrics Online is subject to agreement to the terms and conditions as indicated online. 